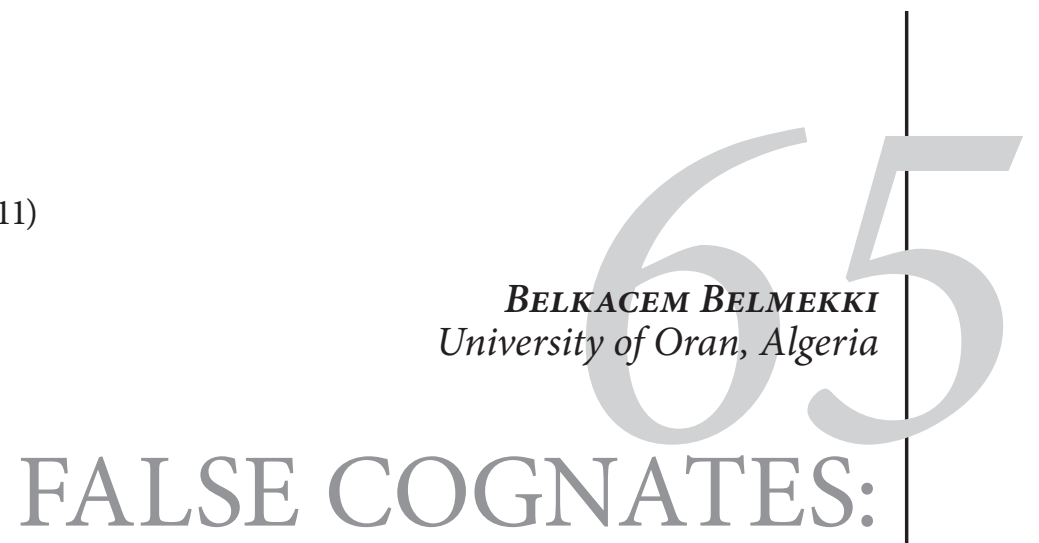

\title{
A MINEFIELD FOR ALGERIAN NON-PROFESSIONAL TRANSLATORS
}

Since Algeria got its independence from the French back in 1962, the successive Algerian Governments have been making a great deal of efforts to try to arabize the Algerian administration. This is well reflected in the series of laws that have been enacted over the last couple of decades which aimed at the promotion of the Arabic language among the Algerian citizens. Probably the most famous one is Act 91-05, which was later modified and complemented by Act 96-30. The latter provides that all administrative correspondence should be in Arabic, and that those who fail to abide by this law would be fined between AD 1,000 and AD 5,000 . Nevertheless, to this day, there are still official papers being issued in French, as well as administrative correspondence being conducted in French. Just go to any company, be it state-owned or private, look at the bulletin board and you will see memoranda written, most of the time, in French rather than in Arabic. This reflects how strong the impact of more-than-a-century long French colonialism was on the Algerian people.

It was in the course of my teaching of Applied Translation module at the UFC (Université de la Formation Continue in Algeria), English Section, that I realised the fact that the French language is still enjoying a predominant place amongst the Algerians. In fact, in this module, students are required to translate texts (most of the time legal texts) from and into English, and the choice of the other language is left open to them, that is, either Arabic or French. Out of 91 students (second as well as third year students) only 3 students opted for Arabic, whereas 88 students opted for French. The only explanation I could give to myself as to this overwhelming tendency to use French rather than Arabic is that it is easier to translate between French and English, due to the fact that these two languages use identical scripts, whereas Arabic uses a different one. Be that as it may, through the translating practice, I noticed that these students were collectively misled by the French-English 'false friends'. So, what are "false friends" then?

Linguists usually use the term "false friends" to refer to those words that exist in two different languages using the same scripts, such as English and French, and which are spelt similarly but have different meanings, such as the English word "actually" and the French word "actuellement". The latter words have totally different meanings, despite the fact that they look alike. As a result, this can cause confusion, as confirmed by Ballard, who talks about "...des interferences qui s'établissent dans le cerveau sous l'effet du principe d'analogie" (1994: 37). 
On the other hand, Granger and Swallow use a different terminology to refer to this sort of confusion. They use the term "deceptive cognates" to designate those "pairs of words which are etymologically related, similar in form but semantically divergent" (Granger \& Swallow 1988: 67).

This difference in meaning despite the likeness of the words in both

languages can be attributed to the fact that after being borrowed from the Latin and Greek languages, these words developed differently (Sheen 1995).

As part of my module, namely Applied Translation, a set of legal texts containing legal terminology was assigned to the students in order to translate into French or English. While correcting their translations, the first thing that struck me was the fact that all of them fell into the trap of 'false friends'.

A false friend may be lexical as well as grammatical. The former is more frequent and more troublesome than the latter as it affects meaning. In fact, when the Algerian learner is faced with a new vocabulary that has its look-alike in French, he then tends to learn it with its French meaning. For instance the word "pain" in English has its false friend "pain" in French, yet the latter means "bread" instead of "ache". As we are concerned with legal translation in this article, illustrations will be restricted to the terminology that is frequently encountered in legal texts.

Lexical false friends can be classified under two major groups: absolute and partial. Absolute false friends, or totally deceptive cognates, as Granger and Swallow (1988) refer to them, tend to cause less confusion when compared to partial false friends. This is due to the fact that the former are those cognates which are completely different at the semantic level and have no common meaning. Using the description of this group of lexical false friends proposed by Sheen (1995), we can draw two circles representing the semantic field of each cognate. These two circles are separate from each other, hence they share no common meaning, as the following diagram for the cognates of the French "dispute" and the English "dispute" illustrates:
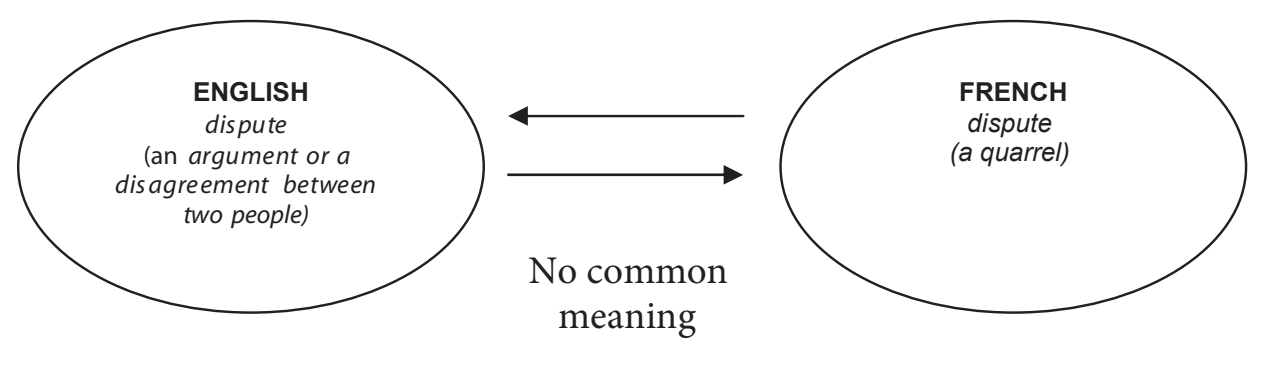

Thus, as depicted in the diagram above, "dispute" in English means an "argument or a disagreement between two people", and its exact translation in French is not "dispute (Fr)" but "litige".

Another example fitting in this category of false friends is the word "officious" (Eng.) and "officieux" (Fr). Whereas in English the word "officious" is an 
adjective that is used to indicate the quality of being "too ready to tell people what to do or to use the power one has to give orders", in French, the word "officieux" means "unofficial".

Also, one can be misled by the French word "recours" and the English word "recourse". In French, "recours" means an "appeal", that is, a formal request to a court of law for a judgment to be changed. Yet, in English, the word "recourse" means "the fact of having to, or being able to, use something that can provide help in a difficult situation."

On the other hand, partial false friends, or partially deceptive cognates, are more complex and I would call them the real "trouble makers". This is because of the fact that the false cognates of both languages, i.e. L1 and L2, have at least one meaning in common and at least one meaning not shared by both. In this regard, Demanuelli \& Demanuelli state:

Seuls les faux amis partiels posent problème dans la mesure ou, à l'inverse des faux amis complets qui n'ont en commun aucun de leurs sens, ils partages avec leurs homologues de la langue cible certain sens (1991: 236).

Again in this respect, Sheen (1995) describes this category of false friends with two intersecting circles, or one circle inside the other one (in this article, the latter are labelled as the outer and inner circle). In the case of two intersecting circles, the area of intersection represents the semantic field that is shared by both cognates, as indicated in the following diagram:

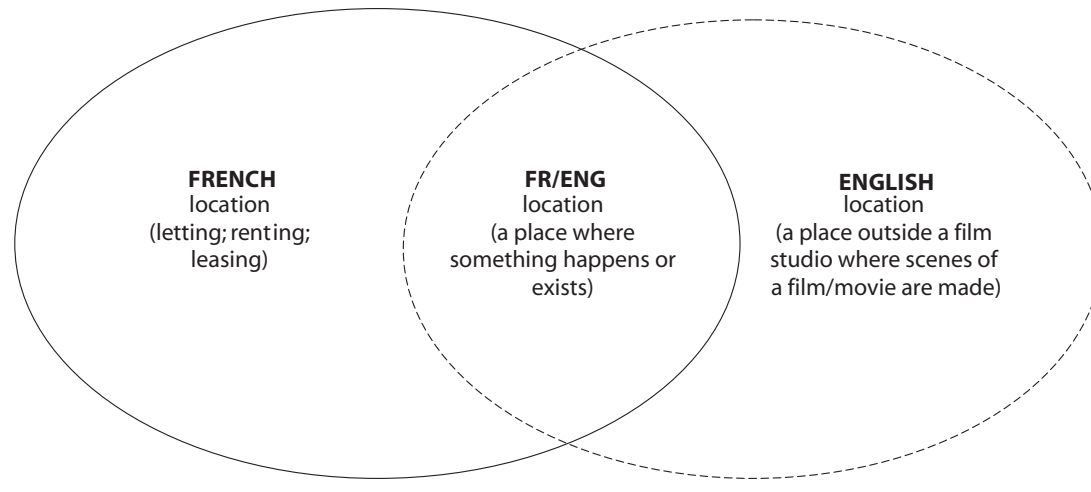

In the case of an "outer and inner circle situation", that is, one circle inside the other, the outer circle has the same meaning as the one inside, besides an additional meaning that it, i.e. the outer circle, does not share with the inner circle. In other words, the outer circle has a wider semantic field than the inner circle, as displayed in the diagram below: 


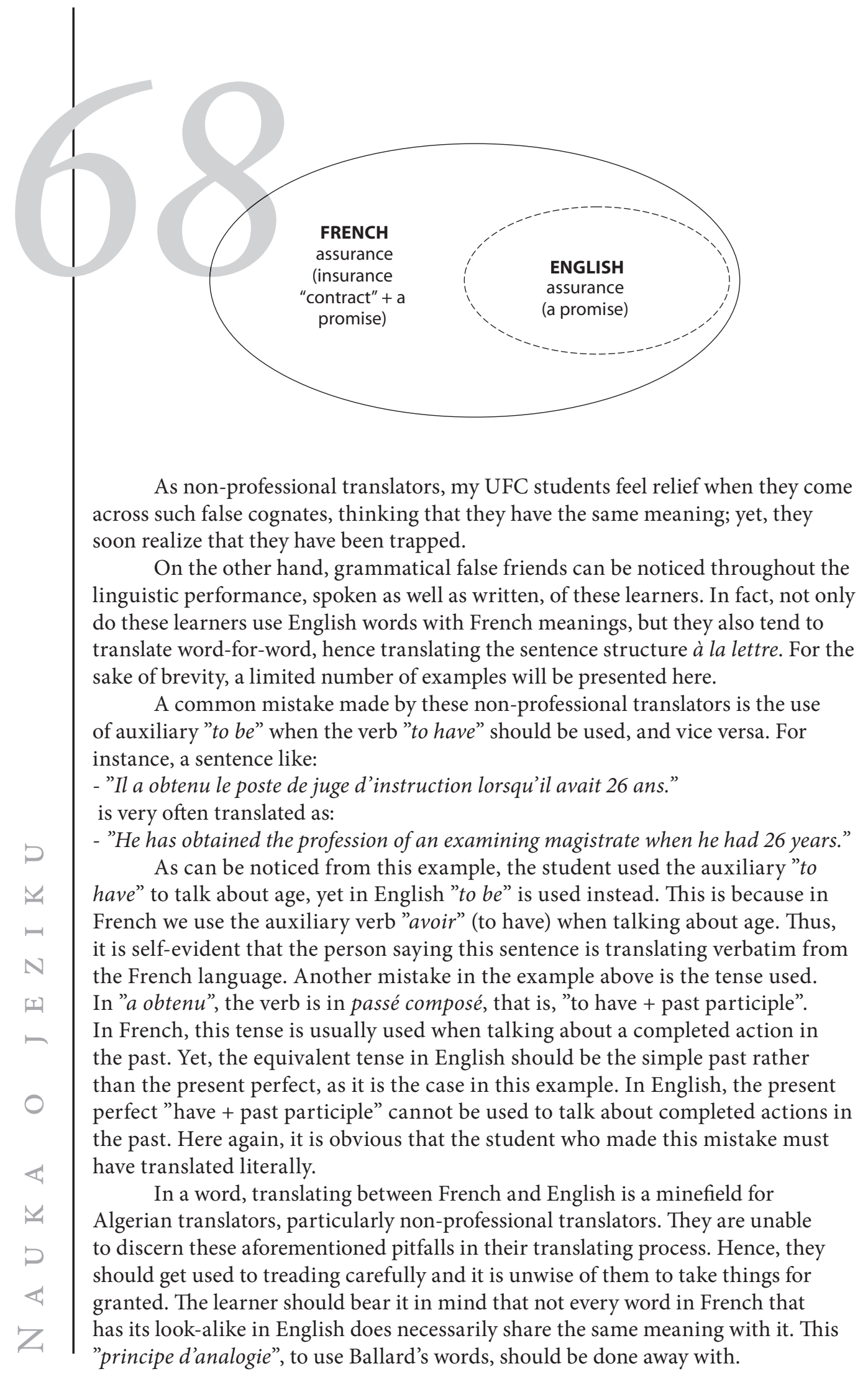




\title{
R E F E R E N C E S
}

Ballard, M. 1994. La Traduction de l'Anglais au Français. France: Nathan. Granger, S. \& H. Swallow. 1988. False friends: a kaleidoscope of translation difficulties. Le Langage et l'Homme 67: 108-120.

Sheen, R. 1995. English faux amis for francophones learning English. [Internet]. Available at: http://www.wfi.fr/volterre/sheen.html [16.9.2006].

Demanuelli, C. \& J. Demanuelli. 1991. Lire et Traduire: Anglais-Français. Paris: Masson.

\section{S U M M A R Y}

FALSE COGNATES: A MINEFIELD FOR ALGERIAN NONPROFESSIONAL TRANSLATORS:

The aim of this paper is to set out a major obstacle, false cognates, faced by many Algerian students wishing to translate from and into French and English.

KEYWORDS: false cognates, faux amis, grammatical/lexical false friends, translation, totally/partially deceptive cognates.

\author{
.
}

